\title{
Synthesis of AIN particles via direct nitridation in a drop tube furnace
}

\author{
Genki SAITO $^{1, \dagger}$, Tatsuya SENDA ${ }^{1}$, Keisuke ABE ${ }^{1}$, Takahiro NOMURA ${ }^{1}$ and Tomohiro AKIYAMA ${ }^{1}$ \\ ${ }^{1}$ Faculty of Engineering, Hokkaido University, Kita 13 Nishi 8, Kitaku, Sapporo 060-8628, Japan
}

\begin{abstract}
We propose a facile and continuous direct nitridation method for synthesizing fine aluminum nitride (AIN) particles using a drop tube furnace. Aerosolized Al powder as the raw material was continuously supplied through the top of the furnace together with $N_{2}$ as a carrier gas. Once in the furnace, the Al powder reacted with the $N_{2}$ to form AIN. A particular advantage of this process is that it allows the continuous synthesis of fine AIN particles. In this study, either a mullite $\left(\mathrm{Al}_{2} \mathrm{O}_{3}-\mathrm{SiO}_{2}\right)$ or an alumina tube was used to fabricate the furnace, and the products were collected in a crucible placed at the bottom. Upon heating the mullite tube from 1200 to $1400^{\circ} \mathrm{C}$, AIN was formed once the temperature exceeded $1250^{\circ} \mathrm{C}$, and its product content increased with temperature. When the flow rate of the $\mathrm{N}_{2}$ carrier gas was decreased from 4 to $2 \mathrm{~L} \mathrm{~min}^{-1}$, the amount of AIN formed increased due to the increased residence time in the reactor. The morphology of the particles obtained was radially aligned nanofibers with droplets on the tips of the fibers. Transmission electron microscopy revealed that the $\mathrm{Si}$ in the mullite tube reacted with Al to form eutectic Al-Si droplets on the Al surface, in which these droplets acted as a catalyst of vapor-liquid-solid AIN fiber growth. When the alumina tube was used $\left(1800^{\circ} \mathrm{C}\right)$, nitridation of $\mathrm{Al}$ was enhanced and radially aligned AIN nanofibers with no droplets on the tips were collected, mainly in a filter at the exhaust port. These AIN nanofibers are thought to form via vapor-solid growth and are easily carried along with the $\mathrm{N}_{2}$ gas flow, resulting in their deposition on the filter. The products collected in the crucible contained coarse Al particles, which are formed via Al particle agglomeration and coarsening through melting.

(O2019 The Ceramic Society of Japan. All rights reserved.
\end{abstract}

Key-words : Fibers (B), Direct nitridation, Drop tube furnace, Nitrides (D)

[Received May 22, 2019; Accepted August 20, 2019]

\section{Introduction}

Aluminum nitride (AIN) is an essential ceramic material with high thermal conductivity, excellent electrical insulative properties, and a low thermal expansion coefficient. ${ }^{1), 2)}$ Because of these favorable characteristics, AlN powders or fibers may be used as highly thermally conductive fillers in resins to improve their heat dissipation. ${ }^{3), 4)}$ AlN sintered bodies are also important substrate materials for integrated circuits. 1),5),6) Currently, $\mathrm{Al}_{2} \mathrm{O}_{3}$ is conventionally used for thermally conductive fillers owing to its low price and high chemical stability. However, its thermal conductivity $(29 \mathrm{~W} / \mathrm{m} \cdot \mathrm{K})^{7)}$ is relatively low compared to that of AIN $(320 \mathrm{~W} / \mathrm{m} \cdot \mathrm{K}){ }^{2}{ }^{2}$ Thus, AlN is a potentially attractive material for use as a thermally conductive filler.

The thermal conductivities of such composites are largely affected by the morphology of the filler. Onedimensional (1D)-structured AIN fibers are considered to be better heat-dissipation fillers than AlN particles because the fibers interconnect to form a network through which heat can be transferred efficiently and easily. ${ }^{8), 9)}$ Furthermore, hybrid fillers comprising both spherical AlN parti-

\footnotetext{
Corresponding author: G. Saito; E-mail: genki@eng. hokudai.ac.jp
}

cles and AlN fibers have been demonstrated to improve the thermal conductivity of their host composite materials. ${ }^{10)}$

AlN powders are synthesized by various methods, such as direct nitridation, ${ }^{11-13)}$ carbothermal reductionnitridation, ${ }^{14)}$ and vapor-phase reactions. ${ }^{15)}$ Among the various methods available, carbothermal reductionnitridation and direct nitridation are most commonly used in industry. For synthesis of AIN by direct nitridation, Al powder is reacted with $\mathrm{N}_{2}$ gas. The nitridation reaction is exothermic $(\Delta \mathrm{H}=-318 \mathrm{~kJ} / \mathrm{mol})$, so once it is initiated with a small input of energy, the reaction proceeds without the need for additional energy from an external source. Thus, direct nitridation including combustion synthesis is a very fast and energy-efficient method for AlN synthesis. ${ }^{16), 17)}$ However, the heat generated by the reaction melts the $\mathrm{Al}$ powder used as the raw material, and the resulting Al agglomerates prevent the nitridation reaction from reaching completion. In addition, the high reaction heat causes sintering and growth of AlN grains. Consequently, a pulverization step is required before using as AlN a raw material for sintered bodies and thermally conductive fillers, and this step often introduces impurities.

A drop tube furnace (DTF) consists of a feeder for the introduction of raw materials, a vertical electric furnace, a reaction tube, and a sample collection device. In DTF 

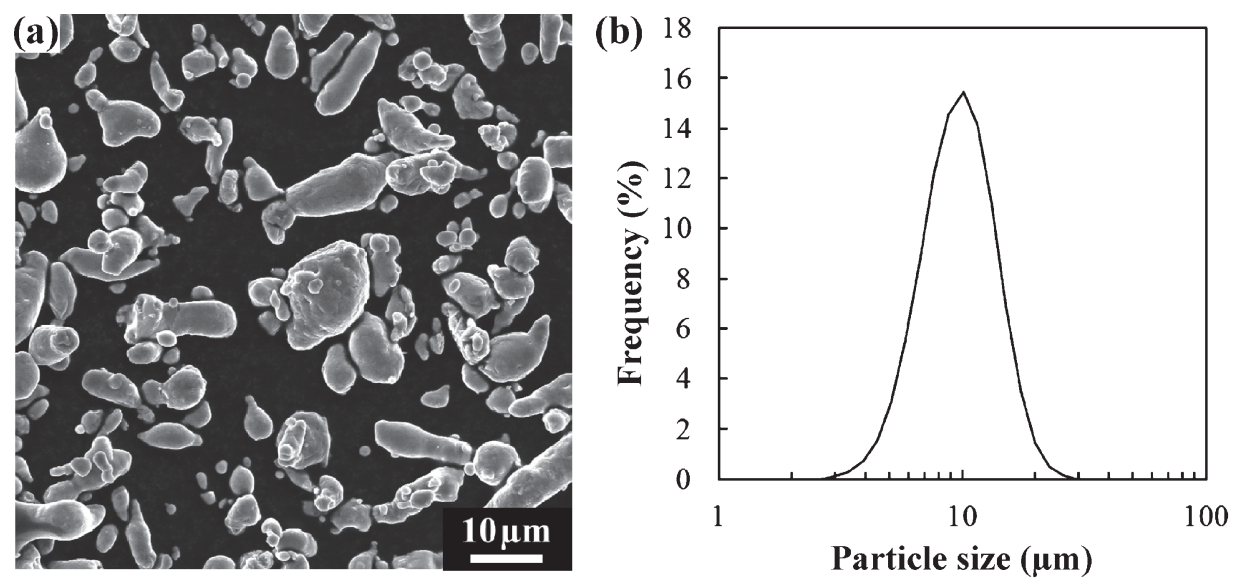

Fig. 1. (a) SEM image and (b) particle-size distribution of the Al powder used as raw material.

processes, the raw materials are continuously supplied through the top of the DTF and are heated as they drop. DTF processes are continuous and thus allow high productivity. Accordingly, DTFs have been used for biomass pyrolysis, ${ }^{18), 19)}$ destruction of tar, ${ }^{20)}$ coke formation, ${ }^{20)}$ and gasification of coal char. ${ }^{21)}$

DTF processes also have attractive features for AlN production. When $\mathrm{Al}$ powder is fed into a $\mathrm{N}_{2}$-filled DTF, direct nitridation occurs without agglomeration, resulting in the formation of fine AIN particles. Furthermore, because the sintering and growth of AIN grains are suppressed, no pulverization step is required. In addition, the Al powder does not come into contact with the reaction chamber as it drops, so the resulting product is typically of high purity.

In this study, we explored the possibility of AlN synthesis by direct nitridation in a DTF. We used a mullite $\left(\mathrm{Al}_{2} \mathrm{O}_{3}-\mathrm{SiO}_{2}, 1200-1400^{\circ} \mathrm{C}\right)$ or an alumina tube $\left(1800^{\circ} \mathrm{C}\right)$ as the reactor tube. To evaluate the potential of DTF methodology for AlN production, we investigated how the reaction-tube material and $\mathrm{N}_{2}$ flow rate affected the synthesized AlN. The products were collected in a crucible placed at the bottom of the furnace and on a filter in the dust collector. Finally, the mechanism of formation for each reaction product was considered based on observation, phase analysis, and particle size analysis.

\section{Materials and methods}

Atomized Al powder $(99.9 \%, \mathrm{Fe} 0.08$ mass $\%$, Si 0.02 mass $\%, 3 \mu \mathrm{m})$ was purchased from Kojundo Chemical Laboratory Co., Ltd. (Saitama, Japan) and used as the raw material. The heterogeneous powder was comprised of spherical and non-spherical particles, as shown by the scanning electron microscopy (SEM) image and particlesize distribution in Fig. 1. A schematic diagram of the DTF is shown in Fig. 2. The reactor consisted of a micron feeder, an ejector, a reaction tube, a filter, and a crucible. The quantity of $\mathrm{Al}$ powder fed into the furnace was controlled with a Micron TF-70-CT rotary valve feeder (Aisin Nano Technologies Co., Ltd., Japan). The Al powder was supplied to the reaction apparatus through an upwardfacing nozzle. The powder was ejected through the nozzle

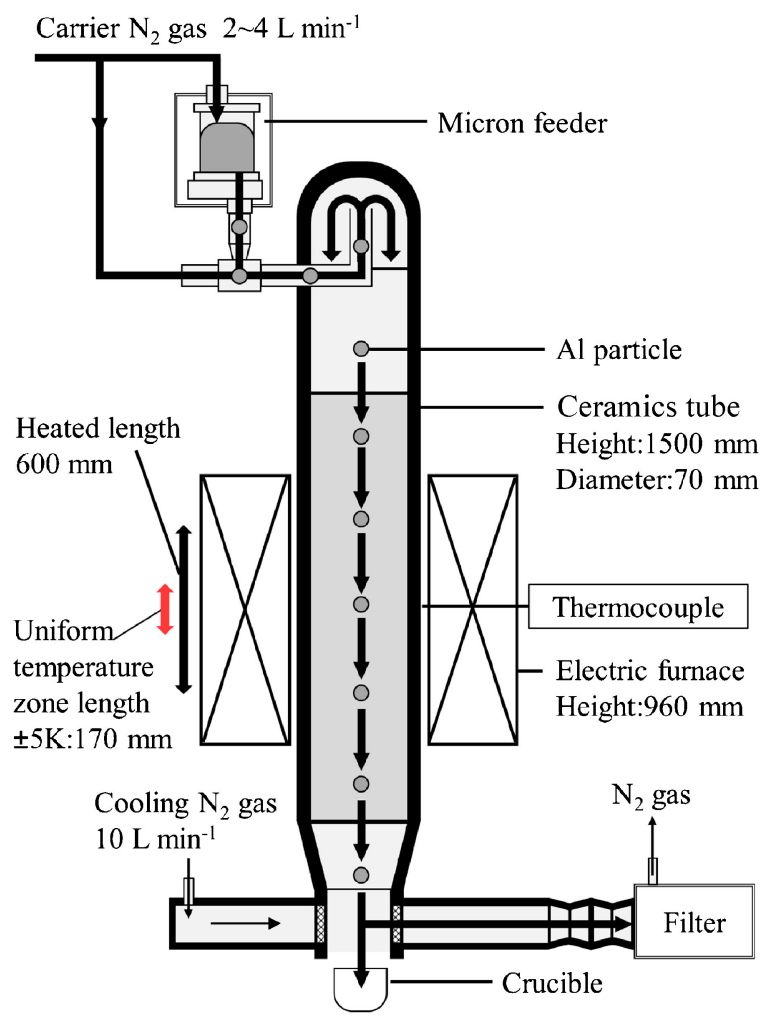

Fig. 2. Schematic illustration of the DTF.

towards the top end of the furnace before introduction into the reactor to decrease its falling velocity. The HB mullite tube (56 mass $\% \mathrm{Al}_{2} \mathrm{O}_{3}$ and 40 mass $\% \mathrm{SiO}_{2}$, Nikkato Corp., Japan) and SSA-S alumina tube (99.6 mass\% $\mathrm{Al}_{2} \mathrm{O}_{3}$, Nikkato Corp., Japan) had an inner diameter of $70 \mathrm{~mm}$, an outer diameter of $80 \mathrm{~mm}$, and a height of $1,500 \mathrm{~mm}$. The temperature of the tube was controlled with an RHTV $120 / 600 / 18$ vertical tubular electric furnace (Nabertherm $\mathrm{GmbH}$, Germany). The height of the furnace was $960 \mathrm{~mm}$, and the length of the heating zone was $600 \mathrm{~mm}$. The uniform temperature zone was $170 \mathrm{~mm}$ in length and the temperature therein could be controlled to within $\pm 5 \mathrm{~K}$. A VF-5N filter (Amano Corp., Japan) was installed to collect samples and discharge gases. 

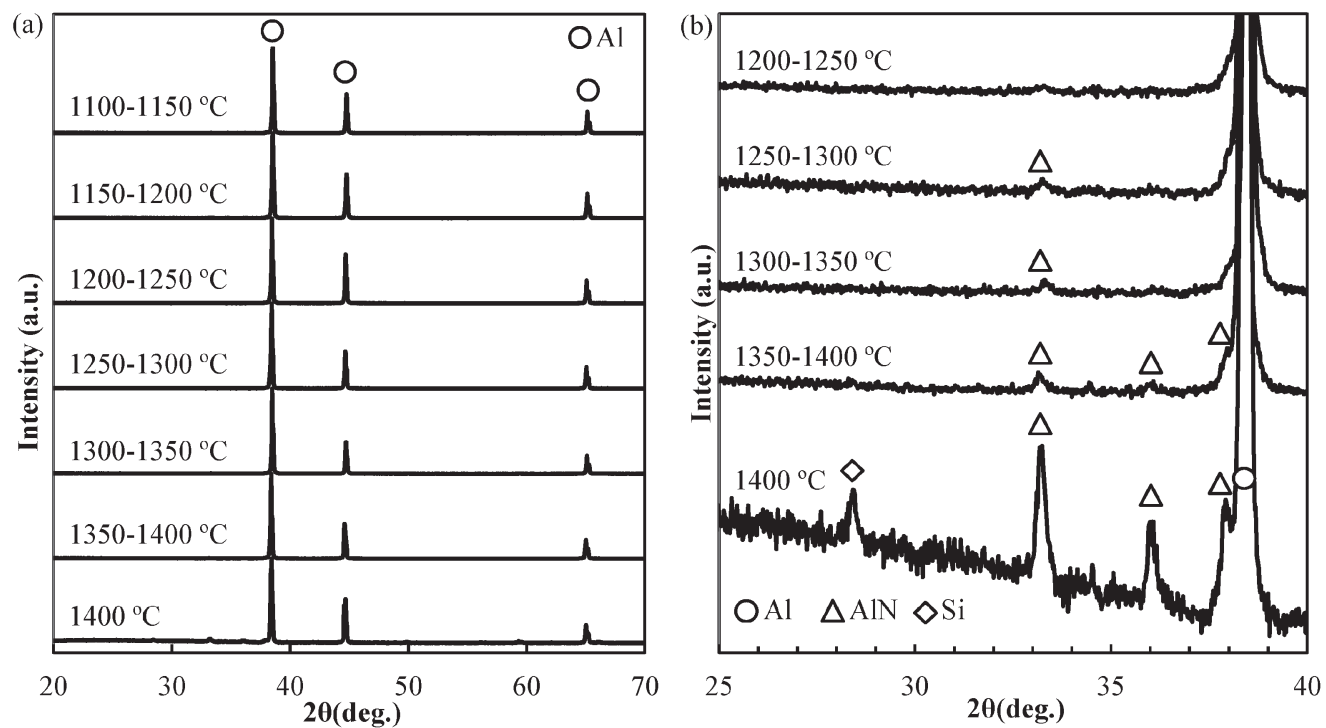

Fig. 3. (a) XRD patterns and (b) an enlargement of the $25-40^{\circ}$ region of products synthesized using a DTF equipped with a mullite reactor tube and under a $\mathrm{N}_{2}$ flow rate of $4 \mathrm{~L} \mathrm{~min}^{-1}$. The products were sieved to a particle size of less than $75 \mu \mathrm{m}$.

The feeder was filled with $\mathrm{Al}$ powder prior to each DTF experiment. $\mathrm{N}_{2}(99.99 \%$, Hokkaido Air Water Inc., Japan) was supplied as the carrier gas at a flow rate of 2 or $4 \mathrm{~L} \mathrm{~min}^{-1}$. When the mullite tube was used, the temperature was increased from 1200 to $1400^{\circ} \mathrm{C}$. For the alumina tube, the DTF was heated to $1800^{\circ} \mathrm{C}$. The $\mathrm{Al}$ powder was dropped continuously into the pre-heated DTF at a supply rate of $0.108 \mathrm{~g} \mathrm{~min}^{-1}$. $\mathrm{N}_{2}$ cooling gas $\left(10 \mathrm{~L} \mathrm{~min}^{-1}\right)$ was circulated at the bottom of the furnace to cool the reaction products and the carrier gas. The products were then collected in the crucible and the filter.

The compositions of the products were determined by X-ray diffraction (XRD) analysis with a MiniFlex 600 diffractometer (Rigaku Corp., Japan). The morphologies of the products were investigated using SEM with a JSM7001FA field-emission SEM (JEOL, Japan). The elemental composition of the products was determined using an SEM apparatus equipped with an energy dispersive spectroscopy (EDS) detector. The particle-size distributions were analyzed with a Partica LA-950 laser diffraction particlesize distribution analyzer (Horiba Scientific, Japan). The nanofibers were observed using a field-emission transmission electron microscope (TEM, JEM-2010F, JEOL) equipped with an EDS detector and an electron energyloss spectroscopy (EELS) detector.

\section{Results and discussion}

\subsection{Results obtained using the mullite reactor tube $\left(1400^{\circ} \mathrm{C}\right)$}

The mullite tube was heated continuously from 1200 to $1400^{\circ} \mathrm{C}$ and the products were collected in the crucible. The flow rate of the $\mathrm{N}_{2}$ gas was fixed at $4 \mathrm{~L} \mathrm{~min}^{-1}$. Figure 3(a) shows the XRD patterns of the collected products, which were sieved to a particle size of less than $75 \mu \mathrm{m}$. Most of the particles were found to be unreacted Al. Figure 3(b) shows an enlargement of the $25-40^{\circ}$ region of the XRD pattern in Fig. 3(a), where the peaks are normalized by the maximum intensity of the $\mathrm{Al}$ peak. A small amount of AlN was detected following reaction at $1250^{\circ} \mathrm{C}$, and the relative intensity of the AlN peak against that of the $\mathrm{Al}$ peak increases with an increase in temperature. At $1400^{\circ} \mathrm{C}$, some metallic $\mathrm{Si}$ is also observed. Figure 4 shows the AlN weight ratios for the products obtained at different temperatures as calculated by the reference intensity ratio (RIR) method based on the XRD results. Clearly, a high reaction temperature enhances nitridation.

Figure 5 shows the SEM images of the products produced at different temperatures. When the temperature is below $1250^{\circ} \mathrm{C}$ [Figs. 5(a)-5(c)], the product morphologies are largely similar to those of the raw materials shown in Fig. 1(a). However, for reactions preformed at 1200$1250^{\circ} \mathrm{C}$ [Fig. 5(c)], course spherical particles, which may be formed via agglomeration of liquid $\mathrm{Al}$, are observed. For reactions performed at temperatures over $1250^{\circ} \mathrm{C}$, spherical particles with radially grown fibers appear, as indicated by the arrows in Fig. 5(d). The formation of these radially grown fibers increases with increasing temperature, as shown in Figs. 5(d)-5(g). Figure 5(h) shows an enlarged SEM image of these unique radially-grown fibers.

The effect of $\mathrm{N}_{2}$ flow rate was investigated while keeping the rector temperature constant $\left(1400^{\circ} \mathrm{C}\right)$ and sieving the products to different sizes. Figure 6 shows how the AlN weight ratio changes with particle size. Decreasing the flow rate from 4 to $2 \mathrm{~L} \mathrm{~min}^{-1}$ increases AIN formation. In addition, the smaller particles were found to have higher AlN contents. These results indicate that the residence time of the falling particles in the heating zone relates to the degree of nitridation, with a lower flow rate and a smaller particle size resulting in the production of larger quantities of AlN.

To evaluate how the particle size and carrier gas flow rate affect the AIN content of the product, the residence 


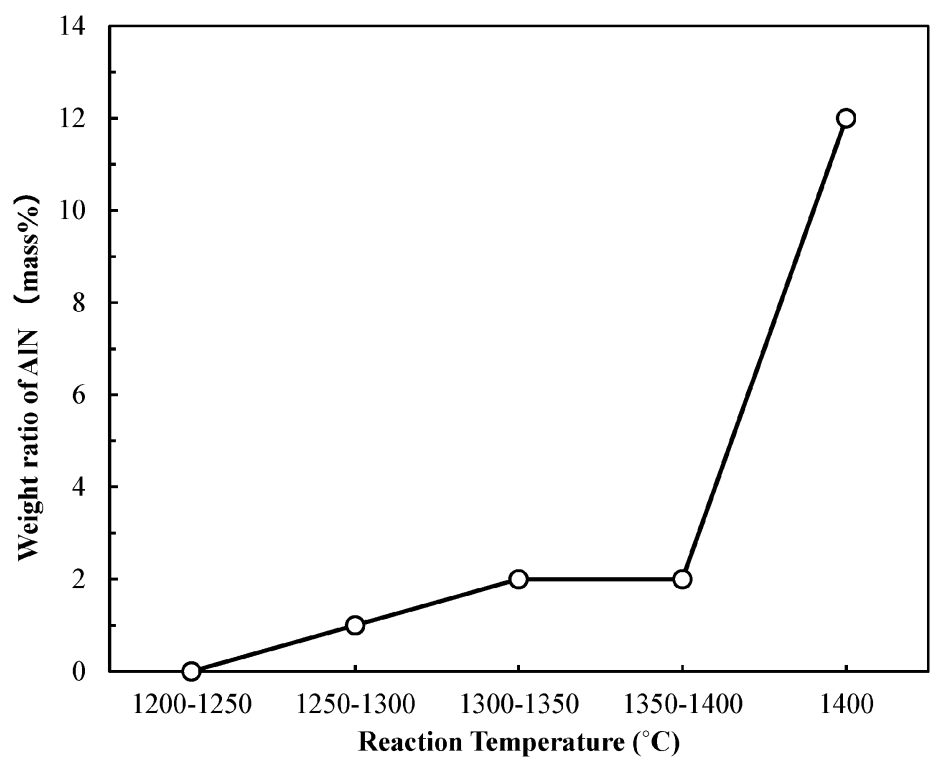

Fig. 4. AlN weight ratios of products synthesized at different temperatures using a DTF equipped with a mullite reactor tube, as calculated using the RIR method based on the XRD results.

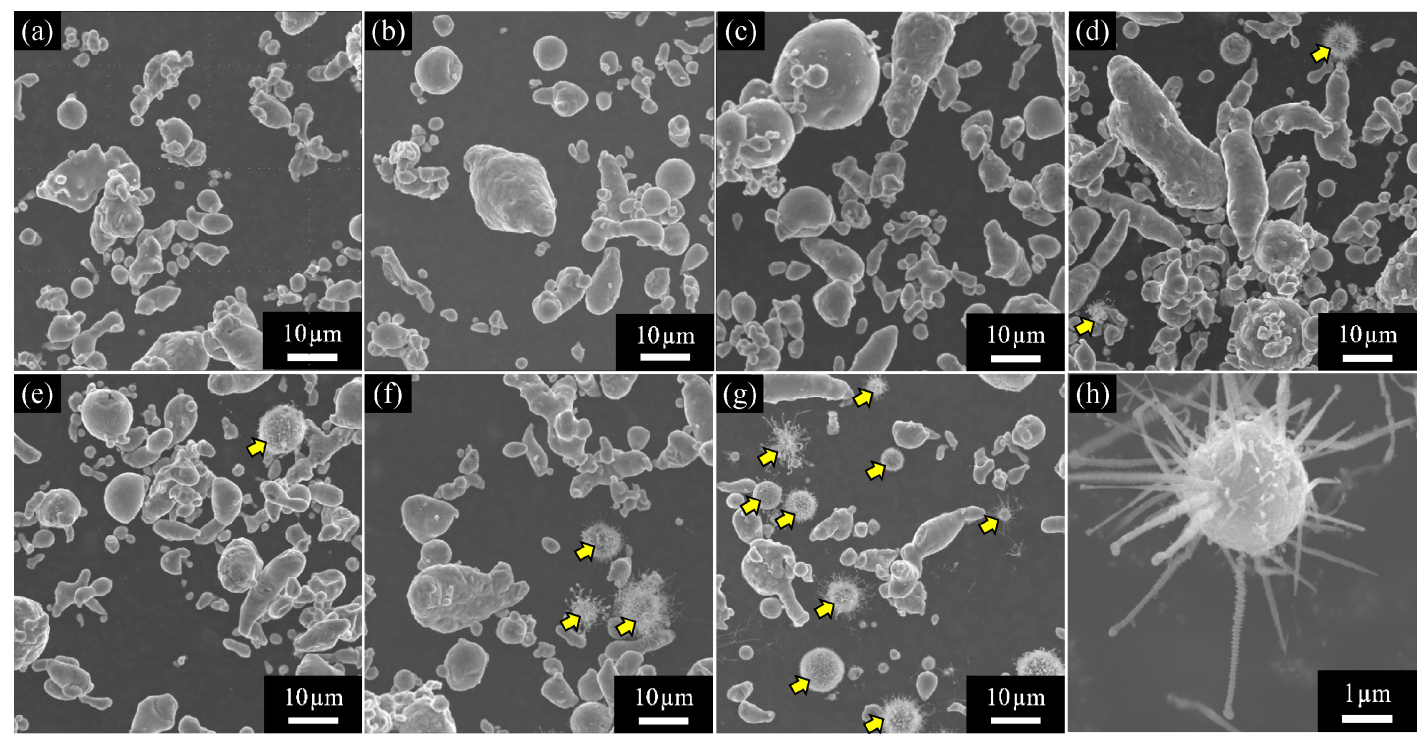

Fig. 5. SEM images of products synthesized using a DTF equipped with a mullite reactor tube and performed reaction temperatures of (a) $1100-1150^{\circ} \mathrm{C}$, (b) $1150-1200^{\circ} \mathrm{C}$, (c) $1200-1250^{\circ} \mathrm{C}$, (d) $1250-1300^{\circ} \mathrm{C}$, (e) 1300 $1350^{\circ} \mathrm{C}$, (f) $1350-1400^{\circ} \mathrm{C}$, and $(\mathrm{g}, \mathrm{h}) 1400^{\circ} \mathrm{C}$. Arrows indicate radially-grown fibers.

time of the $\mathrm{Al}$ particles in the uniform temperature zone of the DTF was calculated assuming that the Al particles are added to the DTF at room temperature. We defined the residence time, $t_{\mathrm{p}}(\mathrm{s})$, as the residence time of $\mathrm{Al}$ particles in the uniform temperature zone and calculated it using Eqs. (1)-(4). ${ }^{22)}$

$$
\begin{aligned}
& U_{\mathrm{p}}=U_{\mathrm{g}}+U_{\mathrm{s}} \\
& U_{\mathrm{g}}=Q / S \\
& U_{\mathrm{s}}=2\left(\rho_{\mathrm{p}}-\rho_{\mathrm{g}}\right) g r_{0}{ }^{2} / 9 \mu \\
& t_{\mathrm{p}}=L / U_{\mathrm{p}}
\end{aligned}
$$

where $U_{\mathrm{p}}$ is the particle velocity $\left(\mathrm{m} \mathrm{s}^{-1}\right), U_{\mathrm{g}}$ is the gas flow velocity $\left(\mathrm{m} \mathrm{s}^{-1}\right), U_{\mathrm{s}}$ is the particle terminal velocity $\left(\mathrm{m} \mathrm{s}^{-1}\right), Q$ is the gas flow rate $\left(\mathrm{m}^{3} \mathrm{~s}^{-1}\right), S$ is the cross- sectional area of the reaction tube $\left(\mathrm{m}^{2}\right), \rho_{\mathrm{p}}$ is the particle density $\left(\mathrm{kg} \mathrm{m}^{-3}\right), \rho_{\mathrm{g}}$ is the gas density $\left(\mathrm{kg} \mathrm{m}^{-3}\right), g$ is acceleration due to gravity $\left(9.8 \mathrm{~m} \mathrm{~s}^{-2}\right),{ }^{23)} r_{0}$ is the mean particle radius $(\mathrm{m}), \mu$ is the viscosity of the carrier gas (Pa s), and $L$ is the length of the uniform temperature zone $(\mathrm{m})$. For these calculations, the Al particle density $\left(\rho_{\mathrm{p}}\right)$ was assumed to be $2,700 \mathrm{~kg} \mathrm{~m}^{-3}$, the $\mathrm{N}_{2}$ gas density $\left(\rho_{\mathrm{g}}\right) 1.25$ $\mathrm{kg} \mathrm{m}^{-3}$, and the $\mathrm{N}_{2}$ gas viscosity $(\mu) 17.6 \times 10^{-6} \mathrm{~Pa}$ s. The calculated residence times of the $\mathrm{Al}$ particles in the uniform temperature zone of the DTF are plotted against particle size in Fig. 7. Smaller particles fall much more slowly than larger particles. Thus, the residence time of smaller particles in the uniform temperature zone is longer, enhancing nitridation. Conversely, larger particles fall at 


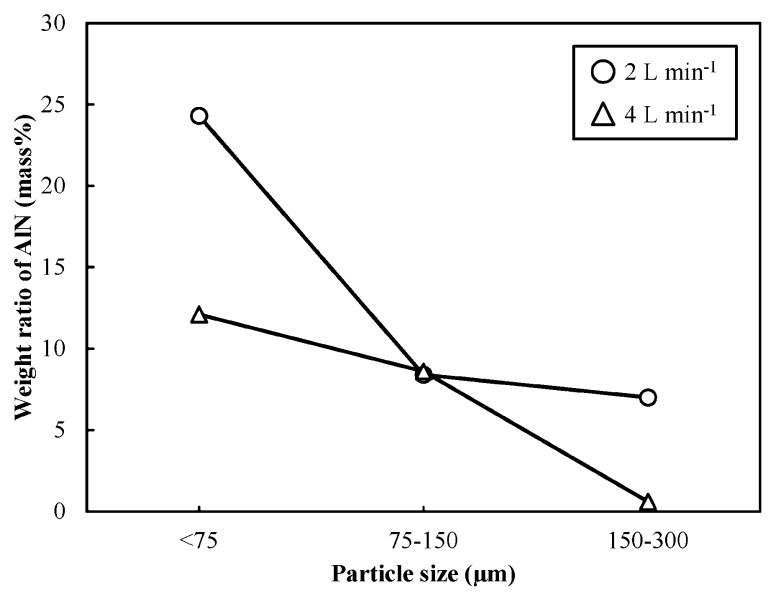

Fig. 6. AlN weight ratios for DTF products with different particle sizes and that were prepared under different $\mathrm{N}_{2}$ flow rates. The weight ratios were calculated using the RIR method based on the XRD results.

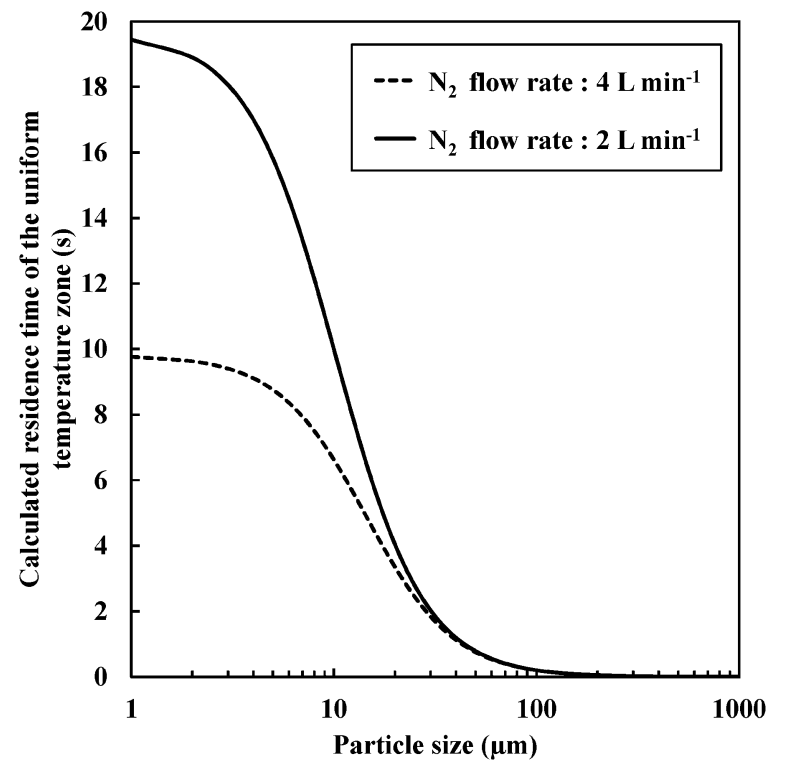

Fig. 7. Calculated particle residence times in the soaking zone of the DTF. Smaller particles have longer residence times and are strongly affected by the $\mathrm{N}_{2}$ flow rate. However, larger particles pass through the soaking zone within a very short time.

higher speeds and thus spend less time in the uniform temperature zone, resulting in inadequate heating and unreacted raw $\mathrm{Al}$ powder.

To investigate the composition of the radially-grown fibers, SEM-EDS analysis was performed. Figure 8 shows the SEM image of the product produced at $1400^{\circ} \mathrm{C}$ with a $\mathrm{N}_{2}$ flow rate of $2 \mathrm{~L} \mathrm{~min}^{-1}$ (the regions analyzed using EDS are indicated by black lettered squares). The results of quantitative EDS analysis are summarized in Table 1. The particles with smooth surfaces mainly consist of Al, as shown in Figs. 8(a), 8(c). In contrast, the particles with radially grown fibers contain $\mathrm{Si}, \mathrm{N}$, and $\mathrm{O}$ [Figs. 8(b), 8(d)]. Figure 9(a) shows a TEM image of these fibers, revealing the presence of spherical particles attached to their tips. The fibers have either a straight or bellows-like

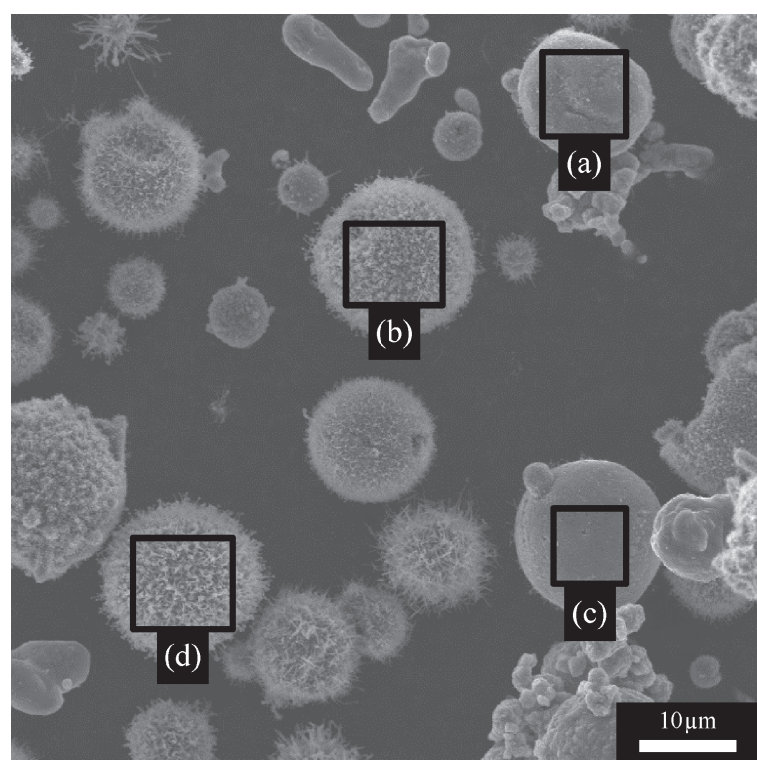

Fig. 8. SEM image of the product synthesized using the mullite reactor tube at $1400{ }^{\circ} \mathrm{C}$ and a $\mathrm{N}_{2}$ flow rate of $2 \mathrm{~L} \mathrm{~min}^{-1}$. The square-highlighted regions are those analyzed by EDS, where (a) and (c) are particles without fibers and (b) and (d) are particles with fibers.

Table 1. Results of quantitative EDS analysis of the DTF products

\begin{tabular}{crrrr}
\hline \multirow{2}{*}{ Sample name } & \multicolumn{4}{c}{ Composition/mass \% } \\
\cline { 2 - 5 } & $\mathrm{Al}$ & $\mathrm{N}$ & $\mathrm{O}$ & $\mathrm{Si}$ \\
\hline (a) & 86 & 9 & 4 & 1 \\
(b) & 61 & 18 & 15 & 6 \\
(c) & 83 & 15 & 1 & 1 \\
(d) & 62 & 15 & 8 & 15 \\
\hline
\end{tabular}

morphology. Figure 9(b) shows a high-resolution TEM image of some representative bellows-like fibers, revealing that the fibers are single crystalline and that no grain boundaries are present in the necks of the bellows. Figures 9(c) and 9(d) show a TEM image and a corresponding electron diffraction patterns, respectively. We confirmed that the fibers have a wurtzite AIN structure and grow in the [001] direction, which is the typical growth direction for AlN fibers.

Subsequently, we focused on the spherical particles attached to the tips of the AlN fibers. Figure 10(a) shows a TEM image of the fibers. The spherical particles are attached to both straight and bellows-like AIN fibers. The EEL spectra were acquired from the selected areas shown in Fig. 10(a). Figures 10(b) and 10(c) show the EEL spectra for $\mathrm{Al}, \mathrm{Si}, \mathrm{N}$, and $\mathrm{O}$. $\mathrm{Al}$ and $\mathrm{Si}$, but not $\mathrm{N}$, were detected in the tip particles. EDS analysis also revealed a similar result. The features of the $\mathrm{Si}-\mathrm{K}$ edge indicate the presence of metallic Si. Based on these results, we concluded that the spherical tip particles are composed of a eutectic AlSi alloy. In Fig. 10(a), the spherical particles on the tips consist of two distinct areas that relate to $\mathrm{Si}$ and $\mathrm{Al}$ phases. In contrast, $\mathrm{Al}$ and $\mathrm{N}$, but not $\mathrm{Si}$, were detected in the fibers, indicating that they are AIN fibers. It has been 
reported that metallic particles can act as metallic catalysts for the vapor-liquid-solid (VLS) growth of fibers. In the case of AlN, Au can act as a catalyst for VLS growth. ${ }^{24)}$ It
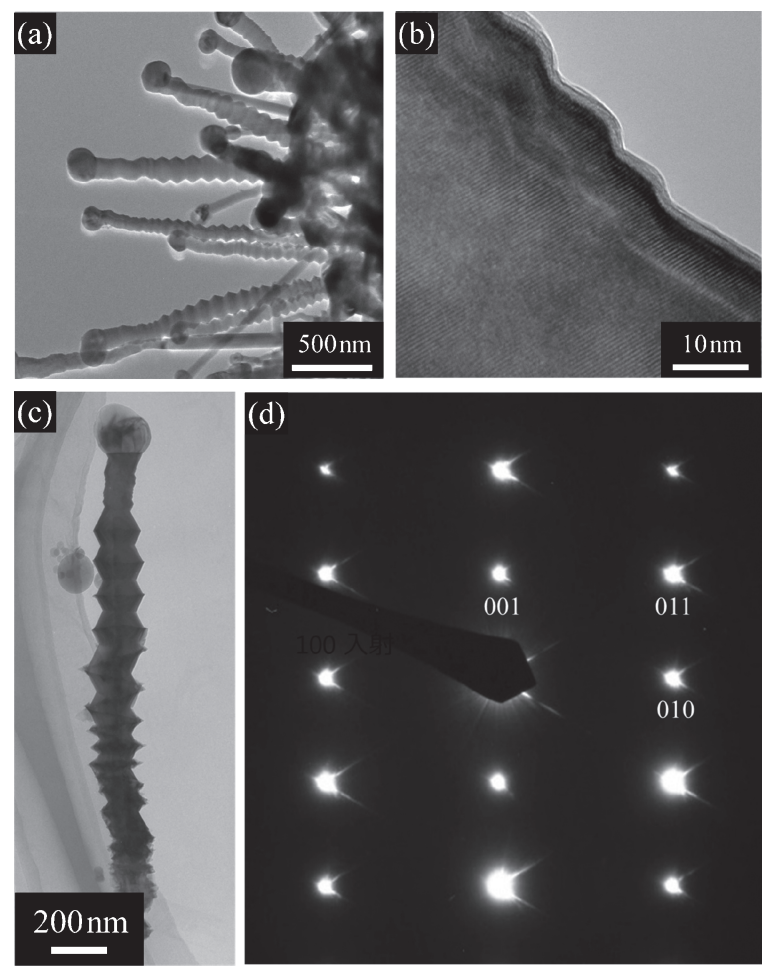

Fig. 9. TEM images of the product synthesized at $1400^{\circ} \mathrm{C}$ and a $\mathrm{N}_{2}$ gas flow rate of $2 \mathrm{~L} \mathrm{~min}^{-1}$. (a) TEM image of the fibers; (b) high-resolution TEM image of bellows-like fibers; (c) TEM image of one single fiber; and (d) selected area electron diffraction pattern from Fig. 9(c). The incident direction of the electron beam was [100]. has also been previously reported that when $\mathrm{MgO}$ is added to the raw materials for the combustion synthesis of AIN, AlN nanowires with $\mathrm{Mg}-\mathrm{Al}-\mathrm{O}-\mathrm{N}$ droplets on the tips are formed, suggesting VLS growth. ${ }^{25)}$

Similarly to these previous studies, VLS growth of AIN occurred in our DTF experiments. Figure 10(d) shows the proposed formation mechanism for radially grown AIN fibers obtained in a DTF using a mullite tube. $\mathrm{Si}$ is attached to the surface of $\mathrm{Al}$ particles and diffuses into $\mathrm{Al}$ to form eutectic Al-Si droplets. However, the vaporization of $\mathrm{Al}$ also occurs at high temperature. Because eutectic Al-Si droplets have a lower melting temperature than that of $\mathrm{Al}$ and $\mathrm{Si}$ alone, they exist as melted droplets, which act as catalysts for VLS growth of AIN fibers. Although Si is an unexpected contamination, it was found that the $\mathrm{Si}$ acts as an effective catalyst of AlN growth during DTF processes.

\subsection{Results obtained using the alumina tube $\left(1800^{\circ} \mathrm{C}\right)$}

When the mullite reactor tube was used, the maximum heating temperature was limited to $1500^{\circ} \mathrm{C}$ and contamination by $\mathrm{Si}$ occurred. Thus, to improve nitridation and product purity, we used an alumina reactor tube. In these experiments, the furnace temperature was set at $1800^{\circ} \mathrm{C}$ and products formed under different flow rate conditions were collected in the crucible and the filter at the exhaust port, as shown in Fig. 2. Due to technical reasons, the material collected from the filter contained products formed at both 4 and $2 \mathrm{~L} \mathrm{~min}^{-1}$ flow rates.

Figure 11(a) shows the XRD patterns of the products collected from the crucible and the filter. The products collected from the crucible were macroscopic grayish powders. Strong Al peaks and weak AIN peaks are present
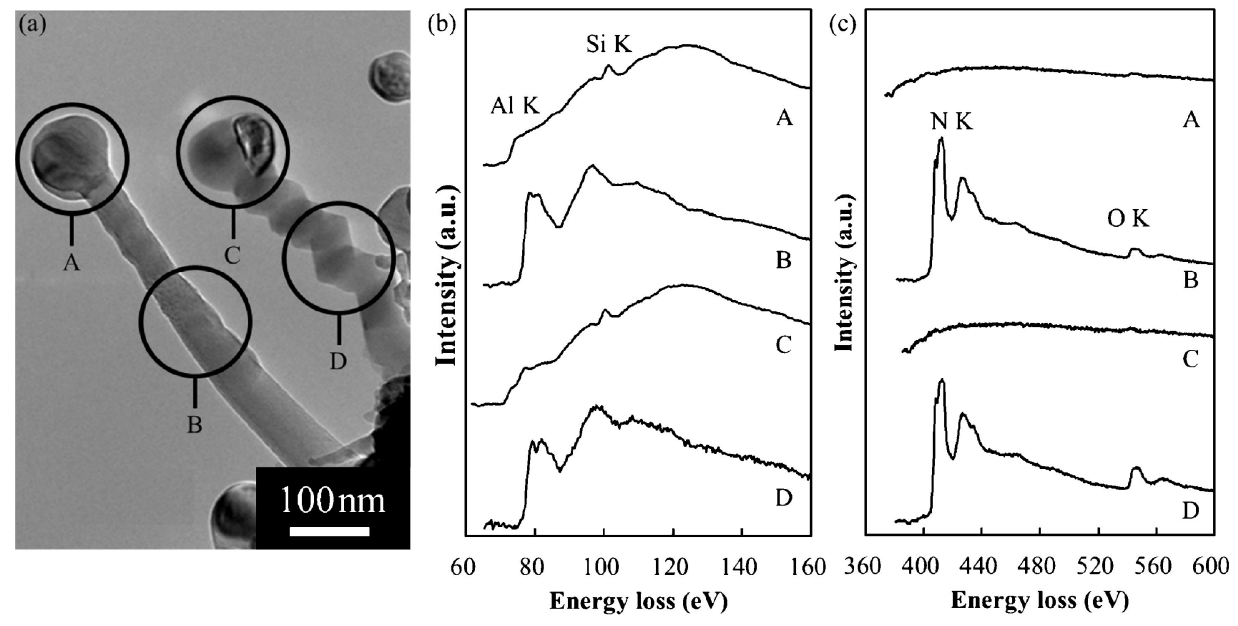

(d)

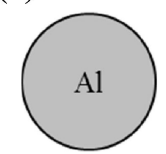

Si from reaction tube

Al-Si eutectic droplets

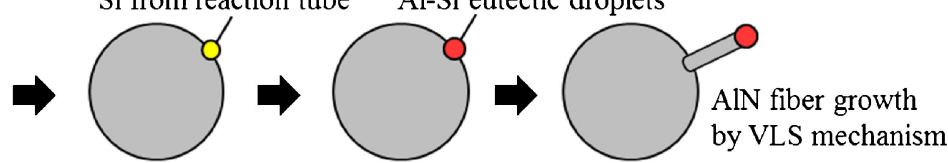

Fig. 10. (a) TEM image of AlN fibers; (b, c) EEL spectra taken from areas A, B, C, and D in Fig. 10(a).

(d) Proposed formation mechanism of radially grown AlN fibers in a mullite tube. 

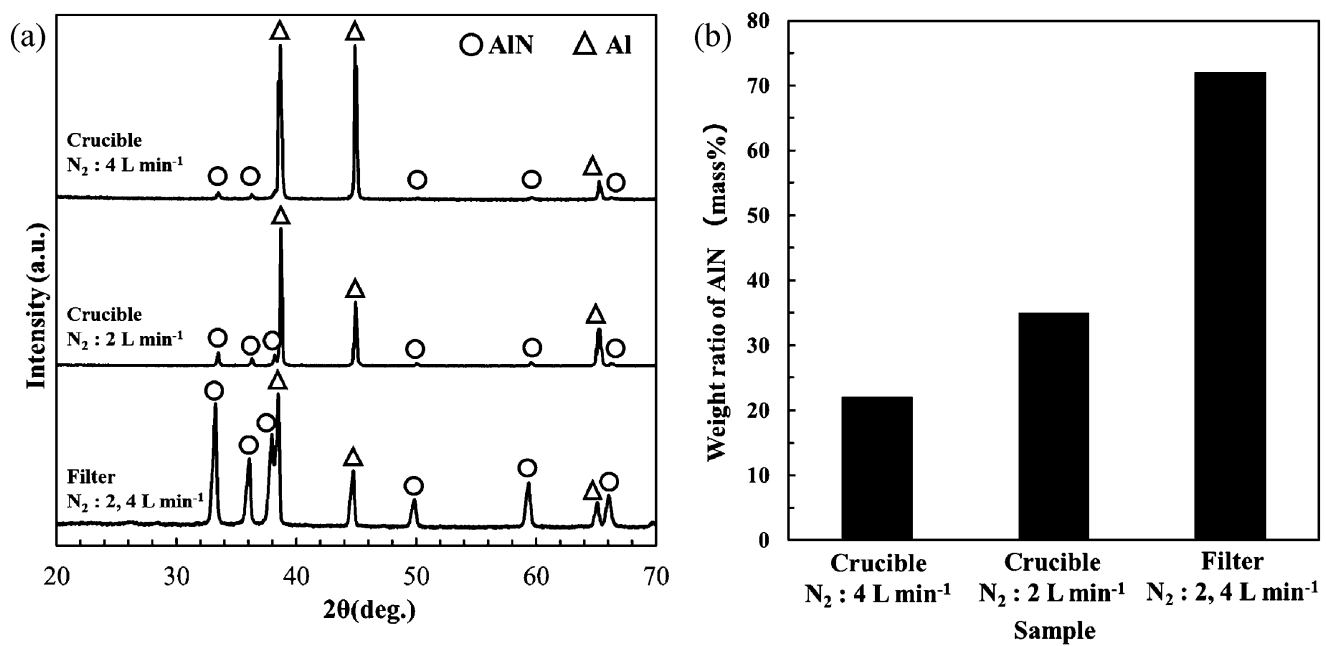

Fig. 11. (a) XRD patterns of products formed using the alumina reaction tube collected from the crucible and filter. AIN is produced under all experimental conditions. (b) The AIN weight ratios for each DTF product as calculated using the RIR method based on the XRD results.

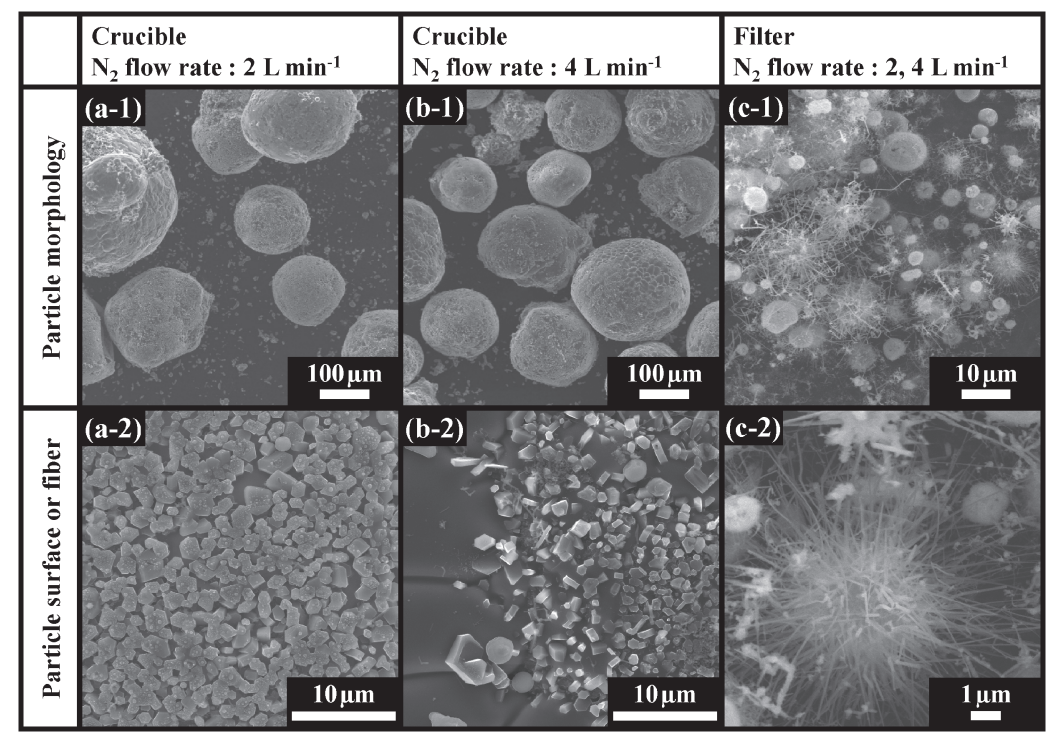

Fig. 12. SEM images of DTF products synthesized using the alumina reactor tube at $1800^{\circ} \mathrm{C}$. (a-1) and (b-1) show the particle morphologies for samples collected from the crucible at different $\mathrm{N}_{2}$ flow rates. The surfaces of the particles are shown at higher magnification in (a-2) and (b-2). (c-1) shows the sample collected from the filter, and (c-2) is an enlarged image of the radially aligned AlN nanofibers.

in the XRD patterns of these powders, indicating that nitridation of the $\mathrm{Al}$ raw material does not complete under the conditions employed. However, upon decreasing the flow rate of the $\mathrm{N}_{2}$ carrier gas from 4 to $2 \mathrm{~L} \mathrm{~min}^{-1}$, the AlN peaks for the synthesized product increase in intensity. The product obtained from the filter in the dust collector was grayish in color and had a cotton-ball morphology. In the XRD pattern of this sample, intense AIN peaks are apparent. This material is clearly different from the product collected in the crucible.

Figure 11(b) shows the AlN weight ratio for each DTF product as calculated using the RIR method based on the XRD results. The product ratio of AIN is higher at the lower carrier gas flow rate. As discussed in Section 3.1, the dropping speed is slower for the lower $\mathrm{N}_{2}$ flow rate, allow- ing the Al powder to be maintained at a high temperature for a longer period of time. The sample collected from the filter had the highest AIN content of $72 \%$ by mass.

SEM images of the DTF products synthesized at $1800^{\circ} \mathrm{C}$ with $\mathrm{N}_{2}$ flow rates of 2 and $4 \mathrm{~L} \mathrm{~min}^{-1}$ are shown in Fig. 12. The particles collected in the crucible [shown in Figs. 12(a-1)-12(b-1)] are relatively large $(>50 \mu \mathrm{m}$ in diameter), whereas the raw $\mathrm{Al}$ powder particles were $3 \mu \mathrm{m}$ in diameter. In addition, all of these coarse particles are spherical, while the Al particulates in the raw material were non-spherical. This indicates that the Al powder supplied through the top of the DTF melts in the heating zone, resulting in aggregation and coarsening. Furthermore, these agglomerated particles melt at high temperature to form coarse spheres. 
We subsequently focused on the surfaces of these particles, which are shown in Figs. 12(a-2)-12(b-2). Hexagonal crystals less than $5 \mu \mathrm{m}$ in size are observed on the particle surfaces. AlN has a hexagonal crystal structure, indicating that these particles are AIN crystals. Owing to the short reaction time, this AIN does not grow into fibers. Conversely, the product particles collected from the filter are smaller than those collected from the crucible, as shown in Fig. 12(c-1). Because the crucible was located at the bottom of the furnace (Fig. 2), the coarse particles fall directly into the crucible. In contrast, smaller particles can be transported by the cooling gas. This is why the smaller particles collect on the filter. The radially aligned nanofibers are found mainly in the products collected from the filter. The cotton-like morphology of the product collected from the filter is a consequence of their fibrous structure.

An enlarged SEM image of the radially aligned nanofibers is shown in Fig. 12(c-2). The numerous fibers grow radially to form spheres. However, no droplets are observed on the tips of the fibers. According to the EDS analysis, $\mathrm{Si}$ is not detected. Therefore, the mechanism for formation of AlN fibers in the alumina tube is differ from that in the mullite tube. The surface of an Al particle is covered with a native oxide film, and heating causes the Al within to melt, subsequently expanding and disrupting the native oxide film. Al vapor is released from cracks on the particle surface, which reacts with $\mathrm{N}_{2}$, and AlN fibers are formed by vapor-solid growth. We believe that this is a rational mechanism for the formation of these fibers.

\section{Conclusions}

In this study, $\mathrm{Al}$ powder and $\mathrm{N}_{2}$ gas were used as raw materials for the synthesis of AlN fine powders in a DTF. A lower $\mathrm{N}_{2}$ flow rate and smaller particle size increase the residence time of the $\mathrm{Al}$ particles in the heated zone of the furnace, enhancing the nitridation of the $\mathrm{Al}$ powder. The mechanism of AlN synthesis depends on the material from which the reaction tube of the DTF is fabricated. In the case of the mullite tube, radially-aligned nanofibers with droplets on their tips are formed at $1400^{\circ} \mathrm{C}$. TEM investigation revealed that $\mathrm{Si}$ from the mullite tube reacts with Al to form eutectic Al-Si droplets on the Al surface, which act as a catalyst for VLS growth of AlN fibers. When an alumina reactor tube is employed at $1800^{\circ} \mathrm{C}$, a predominance of coarse $\mathrm{Al}$ particles is collected from the crucible. When Al particles agglomerate as they drop, they melt and form coarse particles. Radially aligned AIN nanofibers with no droplets on their tips are thought to form via vapor-solid growth and are easily carried along with the $\mathrm{N}_{2}$ gas flow, resulting in their collection on the filter. This seems to suggest that the suppression of Al particle agglomeration is needed to realize the synthesis of highpurity fine AlN powders.

Acknowledgements We would like to thank TAIYO NIPPON SANSO Corp. for the technical assistance, espe- cially in the design and development of the DTF, and for their helpful suggestions.

\section{References}

1) W. Werdecker and F. Aldinger, IEEE T. Compon. Hybr., 7, 399-404 (1984).

2) G. A. Slack, R. A. Tanzilli, R. O. Pohl and J. W. Vandersande, J. Phys. Chem. Solids, 48, 641-647 (1987).

3) Y. Nagai and G.-C. Lai, J. Ceram. Soc. Jpn., 105, 197200 (1997).

4) M. Ohashi, S. Kawakami, Y. Yokogawa and G.-C. Lai, J. Am. Ceram. Soc., 88, 2615-2618 (2005).

5) Y. Kurokawa, K. Utsumi, H. Takamizawa, T. Kamata and S. Noguchi, IEEE T. Compon. Hybr., 8, 247-252 (1985).

6) F. Miyashiro, N. Iwase, A. Tsuge, F. Ueno, M. Nakahashi and T. Takahashi, IEEE T. Compon. Hybr., 13, 313-319 (1990).

7) D. L. Perry, "Handbook of inorganic compounds", CRC press (2016).

8) Z. Shi, M. Radwan, S. Kirihara, Y. Miyamoto and Z. Jin, Appl. Phys. Lett., 95, 224104 (2009).

9) Y. Xu, D. D. L. Chung and C. Mroz, Compos. Part A-Appl. S., 32, 1749-1757 (2001).

10) T. M. L. Dang, C.-Y. Kim, Y. Zhang, J.-F. Yang, T. Masaki and D.-H. Yoon, Compos. Part B-Eng., 114, 237-246 (2017).

11) Y. Kameshima, M. Irie, A. Yasumori and K. Okada, Solid State Ionics, 172, 185-190 (2004).

12) K. Komeya, N. Matsukaze and T. Meguro, J. Ceram. Soc. Jpn., 101, 1319-1323 (1993).

13) T. Sakurai, O. Yamada and Y. Miyamoto, Mat. Sci. Eng. A-Struct., 415, 40-44 (2006).

14) K. Komeya, E. Mitsuhashi and T. Meguro, J. Ceram. Soc. Jpn., 101, 377-382 (1993).

15) I. Kimura, N. Hotta, H. Nukui, N. Saito and S. Yasukawa, J. Ceram. Soc. Jpn., 96, 206-210 (1988).

16) G. Saito, Y. Kunisada, T. Watanabe, X. Yi, T. Nomura, N. Sakaguchi and T. Akiyama, J. Am. Ceram. Soc., 102, 524-532 (2019).

17) A. Hiranaka, X. Yi, G. Saito, J. Niu and T. Akiyama, Ceram. Int., 43, 9872-9876 (2017).

18) Y. Zhang, S. Kajitani, M. Ashizawa and K. Miura, Energ. Fuel., 20, 2705-2712 (2006).

19) W.-H. Chen, S.-W. Du, C.-H. Tsai and Z.-Y. Wang, Bioresource Technol., 111, 433-438 (2012).

20) Y. Zhang, S. Kajitani, M. Ashizawa and Y. Oki, Fuel, 89, 302-309 (2010).

21) S. Kajitani, S. Hara and H. Matsuda, Fuel, 81, 539-546 (2002).

22) N. Takeuchi, Y. Nomura, K.-i. Ohno, T. Maeda, K. Nishioka and M. Shimizu, ISIJ Int., 47, 386-391 (2007).

23) N. A. O. o. Japan, "Chronological Scientific Tables 2017”, Maruzen Publishing Co., Ltd., Tokyo (2016).

24) L. Yu, Y. Lv, X. Zhang, Y. Zhang, R. Zou and F. Zhang, J. Cryst. Growth, 334, 57-61 (2011).

25) Z. Shi, M. Radwan, S. Kirihara, Y. Miyamoto and Z. Jin, J. Ceram. Soc. Jpn., 116, 975-979 (2008). 